\title{
Tree and crop fine root distribution and belowground competition as affected by a climatic gradient in agroforestry parkland systems in Burkina Faso (West Africa)
}

\author{
Yacouba Noël COULIBALY ${ }^{*}$, Thomas GAISER ${ }^{2}$, Jules BAYALA ${ }^{3}$, \\ Alain P.K GOMGNIMBOU ${ }^{1}$, Hugues Roméo BAZIE ${ }^{4}$ and Gérard ZOMBRE ${ }^{4}$ \\ ${ }^{1}$ Institut de l'Environnement et de Recherches Agricoles (INERA), Station de recherches environnementales et \\ agricoles de Farako-Bâ, 01 BP 910, Bobo-Dioulasso, Burkina Faso. \\ ${ }^{2}$ University of Bonn, Institute of Crop Science and Resource Conservation, Katzenburgweg 5D-53115 Bonn. \\ ${ }^{3}$ World Agroforestry Centre (ICRAF), ICRAF-WCA/ Sahel Node, BP E5118 Bamako, Mali. \\ ${ }^{4}$ Université Ouaga 1 Pr Joseph Ki-Zerbo, Ecole doctorale sciences et techniques, 03 BP 7021, Ouagadougou \\ 03, Burkina Faso. \\ "Corresponding author; E-mail: yacoubacoulibaly2002@yahoo.fr ; Tel: 0022678873475
}

\begin{abstract}
This research assessed precipitation increase along a climactic gradient effect on tree and crop root length densities and belowground competition in parklands systems of Vitellaria paradoxa C. F Gaertn, Parkia biglobosa (Jacq.) Benth with Sorghum bicolor (L.) Moench for formulating parklands management options improving crop productivity. Field experiments were conducted at three sites along an increasing rainfall gradient. Soil samples were taken, roots were washed and sorted by categories and root length density was estimated using the method of Tennant. Belowground competition was assessed using the ratio method. Correlation between crop root and aboveground biomass was tested. For topsoil, higher crop root length density was at Sokouraba $\left(0.087 \pm 0.007 \mathrm{~cm} . \mathrm{cm}^{-3}\right)$. For subsoil, crop and tree average root length density was higher at Tougouri and were respectively $0.05 \pm 0.009$ and $0.117 \pm 0.021 \mathrm{~cm} . \mathrm{cm}^{-3}$. Trees reduce crop root length density with precipitation increase and more under P. biglobosa. Belowground competition along a climatic gradient and its interaction with zones and tree species was not significantly different. Higher crop root length density obtained at topsoil with precipitation increase did not reduce belowground competition. Tree management options reducing tree roots should be tested on belowground competition along a climatic gradient.
\end{abstract}

(C) 2019 International Formulae Group. All rights reserved.

Key words: precipitation increase, management options, root length.

\section{INTRODUCTION}

The agroforestry parklands systems which are common in the dry savannas of West Africa are defined as landscapes where for centuries farmers have cut down forests for agricultural purposes while selecting, preserving and protecting useful tree species known for their contribution in rural livelihood (Petit, 2003). In such systems, crop performance can be improved under tree canopy depending on the species, density, management, season characteristics, etc. due to the ecosystem services provided by trees (Boffa et al., 2000; Adegeye et al., 2011), but depending on the tree-crop combination, crop performance can also be reduced under tree 
canopies (Boffa et al., 2000; Bayala et al., 2002; Teklehaimanot, 2004; Zomboubré et al., 2005; Sanou et al., 2012; Bazié et al., 2012). The reduction of crop performance under the tree canopy is associated to the competition which occurs at belowground and aboveground levels. The reduction of crop performance in agroforestry parkland system occurs because the layers of the soil are exploited by the two components (Bayala et al., 2004). In this situation both tree and the crop are sharing the same pool for nutrient and water, and it has been found that the competition for these resources causes the poor performance of the less competitive component, which in most cases are the associated crops (Bayala et al., 2008). Then, at belowground level, the distribution of tree and crop fine root densities in different soil layers determine the degree of competition for water and nutrient access in agroforestry systems (van Noordwijk et al., 2002). Under Vitellaria paradoxa C. F Gaertn an important development of associated crop was due to its high root density in top soil (Bayala et al., 2008). The authors reported that this leads to a competition for access to water because of the high rate of evapotranspiration under $V$. paradoxa due to its canopy architecture. The root distribution in different soil layers is modified by environmental conditions and tree management in agroforestry systems (van Noordwijk et al., 2003). Changes in tree and associated crop fine root densities in different soil layers and zones under trees were reported by Sanou (2010) due to the variations of Photosynthetically Active Radiation, soil moisture and temperature. Logbo et al. (2011) reported a decrease and increase of root biomass according to the species as an adaptation mechanism when water becomes limiting. Tree canopy pruning reduces competition for light and for water as tree root densities are temporarily reduced (Bayala et al., 2004). The objective of this research was assessing the effect of precipitation increase along a climatic gradient on tree and crop root length densities distribution, belowground competition and relationship between crop root length density and aboveground biomass in agroforestry parkland systems consisting of Sorghum bicolor (L.) Moench in association with $V$. paradoxa and Parkia biglobosa (Jacq.) Benth. The findings of this study should provide a better insight into belowground competition in parklands systems, an area that has been little studied, for formulating recommendations of parklands management options in the aim to improve crop productivity.

\section{MATERIALS AND METHODS Site description}

Field experiments were conducted at three different sites along an increasing rainfall gradient: Tougouri located at $13^{\circ} 18^{\prime}$ 59" latitude North and $-3^{\circ} 12^{\prime} 1^{\prime \prime}$ longitude West in the Sahelian zone (northern part); Nobere located at $11^{\circ} 33^{\prime} 29^{\prime \prime}$ latitude North and $-1^{\circ} 12^{\prime} 16^{\prime \prime}$ longitude West in the SudanoSahelian savanna (central part) and Sokouraba located at $10^{\circ} 51^{\prime} 00^{\prime \prime}$ latitude North and $-5^{\circ}$ 11' 00" longitude West in the Sudano-Guinean savanna (southern part). The soils of the three sites are generally poor and have low N, MO and $\mathrm{P}$ contents. In addition, they are weakly acidic with low CEC (Table 1). Average rainfall and temperature (year 1980-2013) were $557 \mathrm{~mm}$ and $26.6{ }^{\circ} \mathrm{C}$ in Tougouri respectively, $859 \mathrm{~mm}$ and $25.7^{\circ} \mathrm{C}$ in Nobere, and $1061 \mathrm{~mm}$ and $25.1{ }^{\circ} \mathrm{C}$ in Sokouraba (DGM, 2013). The average rainfall totaled 620, 775 and $927 \mathrm{~mm}$, respectively in Tougouri, Nobere and Sokouraba during the two years (2011 and 2012) of measurements

\section{Experimental design}

The studied parkland systems consisted of an association of $S$. bicolor with two native tree species: P. biglobosa and V. paradoxa. S. bicolor was cultivated in concentric zones from the trunk of each tree species. The area around each of the sampled trees was split into three concentric tree influence zones and a control plot which were:

- Zone A - from tree trunk to half of the crown radius of the tree;

- Zone B - from half of the crown radius of the tree up to the edge of the crown; 
- Zone $\mathrm{C}$ - from the edge of the tree crown up to $3 \mathrm{~m}$ away; and

- Zone H - a control plot for crop in monoculture which was an area of $4 \times 4$ $\mathrm{m}$ situated at least $40 \mathrm{~m}$ away from the edge of the crown and unshaded by any of the surrounding trees at any time of the day throughout the cropping season.

This design was replicated eight times for each tree species at each site to give a total of sixty four (= 8 reps x ( 2 species x 4 zones $))$ tree-by-zone roots and biomass measurements in Sokouraba, Nobere and Tougouri.

\section{Data collection}

For the measurement of S. bicolor and tree root length density, soil sampling was conducted randomly at two points in each of the concentric zones at $10 \mathrm{~cm}$ interval depth up to $50 \mathrm{~cm}$ near $S$. bicolor $(0-10 ; 10-20 ; 20$ $30 ; 30-40$ and $40-50 \mathrm{~cm}$ ) plants using an auger of $5 \mathrm{~cm}$ diameter with a volume of $250 \mathrm{~cm}^{3}$. The two soil samples for the same depth were mixed to have a composite sample of $500 \mathrm{~cm}^{3}$. From this composite sample, roots were washed using the Root Washer (Delta-T, UK) in a laboratory to separate roots from the soil. Roots were then classified in two categories: trees and S. bicolor. The identification of the root colors after washing through visual observation were used for the classification. Sorghum roots were white, trees roots were brown. The weeds roots which diameter is under $2 \mathrm{~mm}$ were excluded. Only fine roots with diameter less than $2 \mathrm{~mm}$ were considered. The root length of trees and $S$. bicolor in centimeter were estimated using the method of Tennant (1975), which implies that roots are spread out on a grid of $1 \mathrm{~cm} \times 1 \mathrm{~cm}$ and the number of intersections of roots with the vertical and horizontal lines are counted. The following formula was used for the calculation of root length:

$$
\begin{aligned}
& \mathrm{L}=\pi \mathrm{ND} / 4 \\
& \text { With: }
\end{aligned}
$$

$\mathrm{N}=$ number of intersections; $\mathrm{D}=$ width (cm) of the grid and $\mathrm{L}=$ root length $(\mathrm{cm})$

When the samples were too small with less than 30 intersections for a grid of $1 \mathrm{~cm}$, direct measurements of the length were taken using a ruler. The root length density in $\mathrm{cm}$ $\mathrm{cm}^{-3}$ was calculated by dividing the root length of each category of roots with the volume of soil used to extract the roots (Bayala et al., 2004).

The quantitative parameter used to assess the degree of belowground competition between sorghum and trees was the ratio between tree root length density and crop root length density in the different soil layers. The higher the ratio, the stronger should be the competition. This belowground competition will be assessed for the topsoil and the subsoil layers.

The relationship between crop root length density and its aboveground biomass was tested to appreciate the importance of root in determining crop performance in agroforestry parklands systems in the aim to appreciate if a reduction of belowground competition through a decrease of tree root could improve crop productivity.

For this study, the topsoil layers considered is the layer $0-20 \mathrm{~cm}$ and the subsoil layers considered is the layer $20-50$ $\mathrm{cm}$.

\section{Statistical Analysis}

The effect of increase of the precipitation along a climatic gradient on tree and crop root length density distribution and interaction with tree species in the different soil layers were tested using the general model of ANOVA. The effects of increase of the precipitation along a climatic gradient and its interaction with tree species and zones under trees on belowground competition were tested using the general model of ANOVA. The analyses have been done using the software XLSTAT 2018. When the differences among the means were significant with ANOVA, they were separated by the test of StudentNewman Keuils at 5\%. The simple linear regression was used to test the relationship between $S$. bicolor root length density and its aboveground biomass production in zones under trees when precipitation increases along a climatic gradient using the software XLSTAT 2018. 
Table 1: Soil characteristics in the three study sites representing the northern (Tougouri), central (Nobere) and southern (Sokouraba) parts of Burkina Faso in West Africa. The values are the average of top $50 \mathrm{~cm}$ soil layer.

\begin{tabular}{lccc}
\hline Parameters & Tougouri & Nobere & Sokouraba \\
\hline$\%$ clay & 42,6 & 33,8 & 56,1 \\
\hline$\%$ Silt & 25 & 25,6 & 23,3 \\
\hline$\%$ Sand & 32,4 & 40,6 & 20,6 \\
\hline CEC (meq/100 g) & 10,13 & 5,81 & 9,34 \\
\hline Organic matter $(\%)$ & 0,43 & 0,39 & 1,05 \\
\hline N content (\%) & 0,03 & 0,02 & 0,07 \\
\hline P content (P-Bray) $(\mathrm{ppm})$ & 2,2 & 9,56 & 5,38 \\
\hline $\mathrm{pH}$ & 5,92 & 6,43 & 5,71 \\
\hline
\end{tabular}

\section{RESUL TS}

The effects of precipitation increase along a climatic gradient on tree and crop root length density in topsoil and subsoil layers

According to the results of ANOVA, there was not a significant difference of tree root length density with the precipitation increase along a climatic gradient at the topsoil layers (Table 2). But the difference of the tree root length density with the precipitation increase along a climatic gradient was very and highly significant for the subsoil layers (Table 2). The tree root length density was significantly smaller at the subsoil layers when precipitation increases along a climatic gradient (Figure 1A).

The ANOVA reveals a very and highly significant difference of S. bicolor root length density with the precipitation increase along a climatic gradient at topsoil and subsoil layers (Table 3). At the topsoil layers, the root length density of $S$. bicolor was significantly higher with the precipitation increase along a climatic gradient (Figure 1A). But at the subsoil layers, the $S$. bicolor root length density was significantly smaller with precipitation increase along a climatic gradient (Figure 1A).
The effect of the interaction between tree species and precipitation increase along a climatic gradient on the tree root length density at the topsoil and subsoil layers was not significant (Table 2). However, the effect of the interaction between tree species and precipitation increase along a climatic gradient on S. bicolor root length density was significant at the topsoil layers, very and highly significant at the subsoil layers (Table 3 ). At the topsoil and subsoil layers, under both tree species, S. bicolor root length density was smaller with the precipitation increase along a climatic gradient, and this reduction was higher under $P$. biglobosa than V. paradoxa (Figure 1B).

\section{The effect of precipitation increase along a climatic gradient on belowground competition}

According to the result of ANOVA, there was not a significant difference of the root length density ratio at the topsoil and subsoil layers with the increase of precipitation along a climatic gradient (Table 4).

According to the result of ANOVA, there was not a significant effect of the interaction between agroforestry system with 
$P$. biglobosa and $V$. paradoxa and the increase of precipitation along a climatic gradient on the ratio of the root length density at the topsoil and subsoil layers (Table 4).

The result of the ANOVA did not show a significant effect of the interaction between zones under trees and precipitation increase along a climatic gradient on the ratio of the root length density at the topsoil and subsoil layers (Table 4).

The effect of precipitation increase along a climatic gradient on the relationship between crop root length density and its aboveground biomass production under trees

The results of the simple linear regression between $S$. bicolor root length density and its aboveground biomass production was significant in zones $\mathrm{B}$ and $\mathrm{C}$ under $P$. biglobosa at the two extremes precipitation levels along the climatic gradient. The relationship between $S$. bicolor root length density and its aboveground biomass production was very significant in zone $\mathrm{B}(\mathrm{P}<0.01)$ and significant in zone $\mathrm{C}(\mathrm{P}$ $<0.05)$ at the lowest precipitation and significant in zones $\mathrm{B}$ and $\mathrm{C}(\mathrm{P}<0.05)$ at the highest precipitation along the climatic gradient. Any significant relationship between $S$. bicolor root length density and its aboveground biomass production was observed in the zones under $V$. paradoxa with precipitation increase along a climatic gradient. The highest coefficient of correlation in zone B were obtained at the lowest precipitation $(84 \%)$ compared to the highest precipitation $(70 \%)$. For the zone $\mathrm{C}$, the coefficient of correlation obtained was quite the same at the lowest precipitation (77\%) and at the highest precipitation (79\%).

Table 2: Results of ANOVA of the effect of precipitation increase along a climatic gradient on tree roots length density (RLD) and interaction with tree species at topsoil and subsoil layers.

\begin{tabular}{|c|c|c|c|c|c|c|}
\hline Layers & Source & DDL & Sum of squares & Mean of squares & $\mathbf{F}$ & $\operatorname{Pr}>\mathbf{F}$ \\
\hline \multirow{2}{*}{010} & Sites & 2 & 0,171 & 0,086 & 1,660 & 0,193 \\
\hline & Sites*Species & 2 & 0,055 & 0,027 & 0,546 & 0,580 \\
\hline \multirow{2}{*}{1020} & Sites & 2 & 0,030 & 0,015 & 0,460 & 0,632 \\
\hline & Sites*Species & 2 & 0,028 & 0,014 & 0,423 & 0,656 \\
\hline \multirow{2}{*}{2030} & Sites & 2 & 0,150 & 0,075 & 9,051 & 0,000 \\
\hline & Sites*Species & 2 & 0,118 & 0,059 & 7,908 & 0,001 \\
\hline \multirow{2}{*}{3040} & Sites & 2 & 0,193 & 0,096 & 7,809 & $\mathbf{0 , 0 0 1}$ \\
\hline & Sites*Species & 2 & 0,000 & 0,000 & 0,008 & 0,992 \\
\hline \multirow{2}{*}{4050} & Sites & 2 & 0,452 & 0,226 & 15,680 & $<0,0001$ \\
\hline & Sites*Species & 2 & 0,022 & 0,011 & 0,744 & 0,477 \\
\hline
\end{tabular}

Significant $=\mathrm{P}<0.05 \quad$ very significant $=\mathrm{P}<0.01 \quad$ highly significant $=\mathrm{P}<0.001$ 

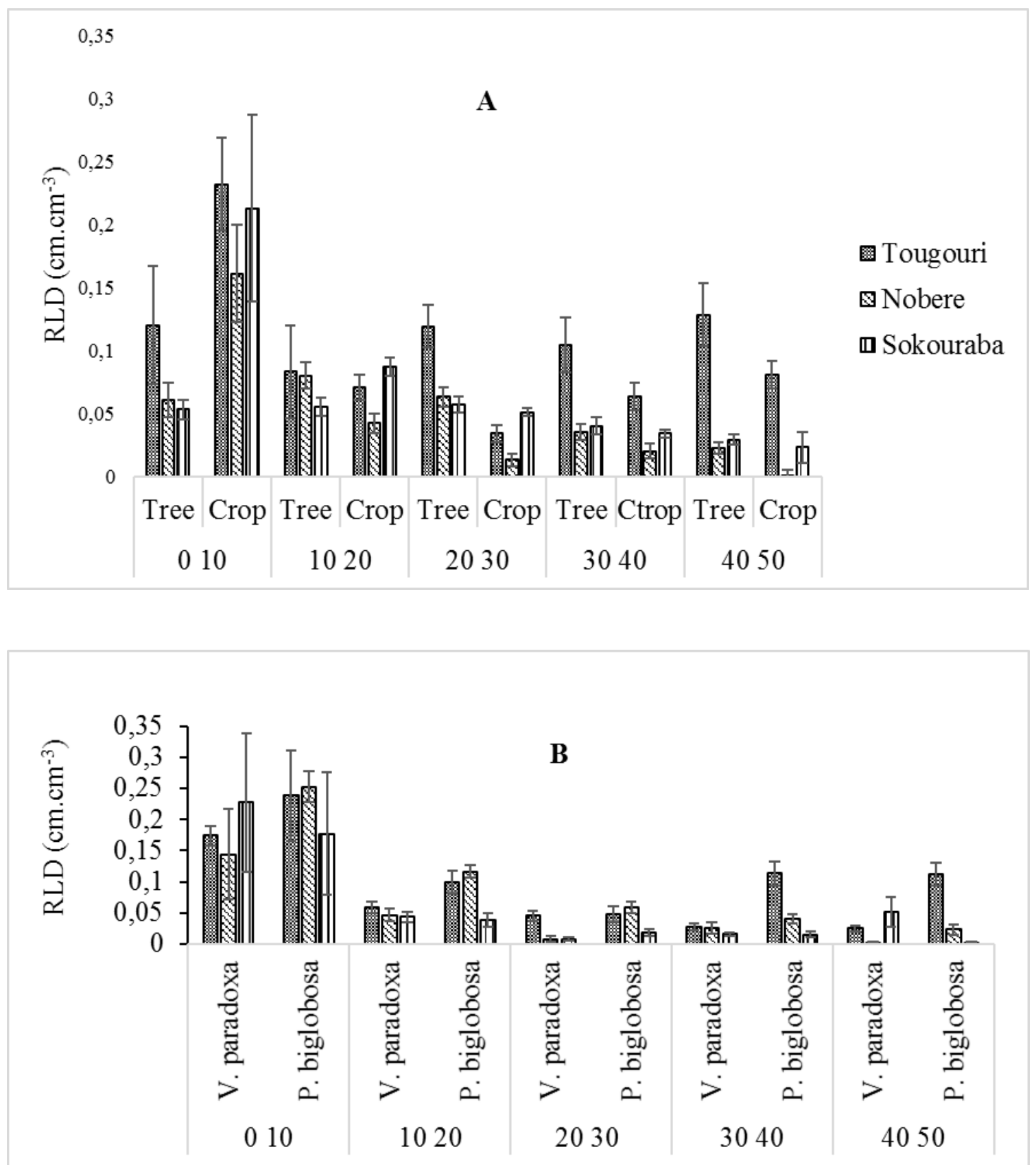

m Tougouri $\mathbf{\text { Q }}$ Nobere $\mathbf{0}$ Sokouraba

Figure 1: (A) Tree and crop root length density (RLD) variation according to the increase of precipitation along a climatic gradient, (B) S. bicolor root length density (RLD) variation according to associated tree species and the increase of precipitation along a climatic gradient. 
Table 3: Results of ANOVA of the effect of precipitation increase along a climatic gradient on Sorghum bicolor roots length density (RLD) and interaction with tree species at topsoil and subsoil layers.

\begin{tabular}{|c|c|c|c|c|c|c|}
\hline Layers & Source & DDL & Sum of squares & Mean of squares & $\mathbf{F}$ & $\operatorname{Pr}>\mathbf{F}$ \\
\hline \multirow{2}{*}{010} & Sites & 2 & 0,177 & 0,089 & 0,496 & 0,610 \\
\hline & Sites*Species & 2 & 0,213 & 0,106 & 0,589 & 0,556 \\
\hline \multirow{2}{*}{1020} & Sites & 2 & 0,067 & 0,034 & 6,383 & 0,002 \\
\hline & Sites*Species & 2 & 0,045 & 0,023 & 4,713 & $\mathbf{0 , 0 1 0}$ \\
\hline \multirow{2}{*}{2030} & Sites & 2 & 0,047 & 0,024 & 10,292 & $<0,0001$ \\
\hline & Sites*Species & 2 & 0,026 & 0,013 & 5,751 & 0,004 \\
\hline \multirow{2}{*}{3040} & Sites & 2 & 0,065 & 0,032 & 8,256 & $\mathbf{0 , 0 0 0}$ \\
\hline & Sites*Species & 2 & 0,070 & 0,035 & 11,049 & $<0,0001$ \\
\hline \multirow{2}{*}{4050} & Sites & 2 & 0,219 & 0,110 & 18,850 & $<0,0001$ \\
\hline & Sites*Species & 2 & 0,151 & 0,076 & 13,386 & $<0,0001$ \\
\hline
\end{tabular}

Significant $=\mathrm{P}<0.05 \quad$ very significant $=\mathrm{P}<0.01 \quad$ highly significant $=\mathrm{P}<0.001$

Table 4: Results of ANOVA of the effect of precipitation increase along a climatic gradient on the ratio between tree root length density (RLD) and crop root length density (RLD) and interaction with tree species and zones at topsoil and subsoil layers.

\begin{tabular}{|c|c|c|c|c|c|c|}
\hline Layers & Source & DDL & Sum of squares & Mean of squares & $\mathbf{F}$ & $\operatorname{Pr}>\mathbf{F}$ \\
\hline \multirow{3}{*}{010} & Sites & 2 & 13,447 & 6,724 & 1,507 & 0,225 \\
\hline & Sites*Species & 2 & 1,354 & 0,677 & 0,152 & 0,859 \\
\hline & Sites*Zones & 6 & 22,061 & 3,677 & 0,838 & 0,542 \\
\hline \multirow{3}{*}{1020} & Sites & 2 & 3,595 & 1,797 & 0,766 & 0,467 \\
\hline & Sites*Species & 2 & 0,709 & 0,355 & 0,151 & 0,860 \\
\hline & Sites*Zones & 6 & 10,014 & 1,669 & 0,845 & 0,538 \\
\hline \multirow{3}{*}{2030} & Sites & 2 & 68,877 & 34,438 & 1,958 & 0,147 \\
\hline & Sites*Species & 2 & 115,734 & 57,867 & 3,290 & 0,421 \\
\hline & Sites*Zones & 6 & 191,668 & 31,945 & 2,153 & 0,055 \\
\hline \multirow{3}{*}{3040} & Sites & 2 & 129,124 & 64,562 & 1,887 & 0,157 \\
\hline & Sites*Species & 2 & 113,790 & 56,895 & 1,663 & 0,195 \\
\hline & Sites*Zones & 6 & 192,794 & 32,132 & 0,995 & 0,433 \\
\hline \multirow{3}{*}{4050} & Sites & 2 & 55,321 & 27,661 & 2,533 & 0,086 \\
\hline & Sites*Species & 2 & 5,078 & 2,539 & 0,232 & 0,793 \\
\hline & Sites*Zones & 6 & 78,743 & 13,124 & 1,185 & 0,324 \\
\hline
\end{tabular}

Significant $=\mathrm{P}<0.05 ; \quad$ very significant $=\mathrm{P}<0.01 ; \quad$ highly significant $=\mathrm{P}<0.001$. 


\section{DISCUSSION}

\section{The effects of precipitation increase along a climatic gradient on tree and crop root length density in topsoil and subsoil layers}

The climatic gradient characterized by the precipitation increase from Tougouri, Nobere and Sokouraba induced changes on trees and S. bicolor root length densities at subsoil layers with higher root length density of trees and S. bicolor observed at Tougouri with the lowest precipitation along a climatic gradient. The increase of trees and S. bicolor root length density at subsoil layers at Tougouri is an adaptation to water deficit. Logbo et al. (2011) reported an increase of Acacia tortilis (Forsk.) Hayne ssp. raddiana (Savi) Brenand root biomass when water becomes limiting as an adaptation mechanism.

At the topsoil layers, there was not a significant difference between trees root length density with the precipitation increase along a climatic gradient but $S$. bicolor root length density was higher at Sokouraba with the highest precipitation along a climatic gradient. This was probably due to the soil physical and chemical properties improved because of the practice of fallow at Sokouraba. Traore et al. (2007) reported a more stable soil structure under fallows than when soils were cultivated. The positive effects of an improved soil physical and chemical properties on crop root development has been reported by Ndiaye et al. (2012). The precipitation increase along a climatic gradient affected differently at the topsoil and subsoil layers tree and crop root length density. The effect of precipitation on tree and crop fine root growth depends on soil physical and chemical properties at topsoil and subsoil layers.

The precipitation amount under trees is under the influence of canopy structure due to the effect of precipitation interception by the canopies. Zomboudre et al. (2005) reported an average reduction of precipitation for about $12 \%$ under $V$. paradoxa with a ball canopy while there was an increase of about $10.3 \%$ under a brush canopy compared to the precipitation out of the canopy. The higher root length density of S. bicolor observed under both tree species canopy at the lowest precipitation along a climatic gradient is then an adaptation to water deficit as reported by Logbo et al. (2011). The interception of precipitation by tree canopy leaded to this water deficit under tree canopy which is severe when the precipitation is low as reported by Zomboudre et al. (2005). The low development of $S$. bicolor root length density under $P$. biglobosa compared to V. paradoxa when precipitation increases along a climatic gradient could be explained by the structure and architecture of its canopy which maintains more humidity under trees due to the reduction of evaporation leading to less root development. Zomboudre et al. (2005) reported higher soil humidity under $V$. paradoxa with a ball canopy compared to brush canopy and out of canopy when precipitations are scarce or abundant. The important humidity in soil under the canopy of $P$. biglobosa due to the dense and compact structure of its canopy (Bayala et al., 2002; Bazie et al., 2012; Sanou et al., 2012) and the good soil chemical properties (Bayala et al., 2002) could explain the low root development of $S$. bicolor. Due to the ascendant architecture of the branches of $V$. paradoxa, more solar irradiation comes to the soil leading to more evaporation in upper soil layers as reported by Bayala et al. (2008). This could explain the high root length density of $S$. bicolor under $V$. paradoxa when precipitation increases. Trees canopy structure is a major factor influencing crop root development under trees at topsoil and subsoil layers when precipitation increases along a climatic gradient through the interception of precipitation which influences soil physical and chemical properties. $S$. bicolor in association with $P$. biglobosa with a dense and compact canopy showed lower root length density and crop root length density decreased under both tree species with the increase of precipitation along a climatic gradient. It could be recommended farmers to promote $V$. paradoxa in the development of new agroforestry systems due to the relative high root length densities of $S$. bicolor obtained under $V$. paradoxa at all the precipitation level 
along a climatic gradient. Several authors reported a better crop performance under $V$. paradoxa than $P$. biglobosa (Bayala et al., 2002; Bazié et al., 2012; Sanou et al., 2012; Coulibaly et al., 2014).

\section{The effect of precipitation increase along a climatic gradient on belowground competition}

The effect of precipitation increase along a climatic gradient and its interaction with tree species and zones on the ratio of the root length density was not significant at the topsoil and subsoil layers. Despite the increase observed in crop fine root growth with precipitation increase at topsoil layers and at subsoil layers when precipitation decreases, it was not sufficient to significantly reduce the belowground competition probably due to the relative importance of tree root length density at topsoil and subsoil layers. The results also showed that in parklands with $V$. paradoxa and $P$. biglobosa in association with $S$. bicolor, the belowground competition for access to water and nutrient is high due to the fact that both tree and crop have their roots in the same layers as reported by Bayala et al. (2004).

The belowground competition in parklands systems seems to be more under the influence of parklands management than climate. For reducing tree and crop belowground competition in the aim to increase crop productivity in agroforestry parkland systems, tree crown pruning which can reduce trees root length density in topsoil soil layer could be tested. Trees crown pruning to reduce or stop belowground tree and crop competition has been reported by Bayala et al. (2004).

\section{The effect of precipitation increase along a climatic gradient on the relationship between crop root length density and its aboveground biomass production under trees}

The relationship between crop root length density and its aboveground biomass production was significant only under $P$. biglobosa at the two extremes of precipitation probably because of the high aboveground competition under its canopy. Sanou (2010) reported that the dense canopy of $P$. biglobosa canopy reduced more light and others environmental conditions under its canopy. The reduction of light under the canopy of $P$. biglobosa is improved as we go beyond the trunk (Sanou, 2010). The improvement of light capture will increase crop photosynthesis leading to a better crop root development. This increase of root development could explain the highest correlation coefficient obtained in the zones B and $\mathrm{C}$ under P. biglobosa at the lowest and highest precipitation along a climatic gradient. At the lowest precipitation, the water stress should be strong leading to higher root development as an adaptation mechanism that could explain the highest correlation coefficient obtained in zone B at the site with the lowest precipitation. These results showed that crop root could determine biomass production and then a reduction of belowground competition under trees in agroforestry parklands through appropriate management options could improve crop productivity.

\section{Conclusion}

This study highlighted the effect of precipitation increase along a climatic gradient on root length density distribution and belowground competition in topsoil and subsoil layers of an agroforestry parkland systems consisted of an association of $S$. bicolor with two native trees, $P$. biglobosa and $V$. paradoxa. The soil physical and chemical properties at the topsoil and subsoil layers are major factors affected by the increase of precipitation along a climatic gradient influencing tree and crop root length density distribution. The architecture of the tree canopy which intercepts the rainfall creating a water stress under trees led to a reduction of crop root length density when precipitation increases along a climatic gradient due to the better conditions for root development and this reduction is higher at the topsoil and subsoil layers under $P$. biglobosa than $V$. paradoxa because of its 
dense canopy. Despite the increase of crop root length density at topsoil with precipitation increase along a climatic gradient, the belowground competition was not reduced probably because of the relative importance of tree root length density at the topsoil and subsoil layers. Belowground competition seems to be more under the influence of parklands management than climate. The study also reveals that root length density of S. bicolor in agroforestry parklands could determine its aboveground biomass productivity. Then, to reduce belowground competition and improve crop productivity in agroforestry parklands, tree management which can reduce tree root length density in topsoil layers could be tested and $V$. paradoxa could be recommended in the development of agroforestry systems. This research confirms that tree root length density is a major factor influencing belowground competition and crop productivity in parklands, suggesting further research focusing on the effect of tree management which reduces its root length density on belowground competition along a climatic gradient.

\section{COMPETING INTERESTS}

The authors declare that they have no competing interests.

\section{AUTHORS' CONTRIBUTIONS}

YNC is the first author of this article. He developed the research protocol, collected and analysed the data and initiated this paper in the framework of his $\mathrm{PhD}$ research. JB and GZ supervised the work of the $\mathrm{PhD}$ studies and they have contributed in revising this paper. TG, APKG and HB have contributed in revising this paper.

\section{ACKNOWLEDGMENTS}

We would like to thank farmers of Tougouri, Nobere and Sokouraba for their valuable contribution in data collection and their attention to the experiments throughout the three years of experiments. We are also grateful to the technicians for their assistance in the data measurements. Thank you to my supervisors for their guidance and advice.

\section{REFERENCES}

Adegeye AO, Jimoh SO, Agera SI. 2011. Agricultural productivity under taungya and non-taungya land-use options: a case study of Vandeikya Local Government area, Benue State, Nigeria. Int. J. Biol. Chem. Sci., 5(6): 2343-2350. DOI: http://dx.doi.org/10.4314/ijbcs.v5i6.14

Bayala J, Teklehaimanot Z, Ouédraogo SJ. 2002. Millet production under pruned tree crowns in a parkland system in Burkina Faso. Agroforest. Syst., 54: 203214.

DOI: https://doi.org/10.1023/A:101605890668 2

Bayala J, Teklehaimanot Z, Ouédraogo SJ. 2004. Fine root distribution of pruned trees and associated crops in parkland system in Burkina Faso. Agroforest. Syst., 60: 13-26. DOI: https://doi.org/10.1023/B:AGFO.000000 9401.96309.12

Bayala J, van Noordwijk M, Lusiana B, Kasanah N, Teklehaimanot Z, Ouédraogo SJ. 2008. Separating the treesoil-crop interactions in agroforestry parkland systems in Saponé (Burkina Faso) using WaNuLCAS. $A d v$. Agroforest., 4: 296-308.

Bazie HR, Bayala J, Zombre G, Sanou J, Ilstedt U. 2012. Separating competitionrelated factors limiting crop performance in an agroforestry parkland system in Burkina Faso. Agroforest. Syst., 84: 377388. DOI: $10.1007 / \mathrm{s} 10457-012-9483-\mathrm{y}$

Boffa JM, Taonda SJ, Dickey JB, Knudson DM. 2000. Field-scale influence of karité (Vitellaria paradoxa) on sorghum production in the Sudan zone of Burkina Faso. Agroforest. Syst., 49: 153-175. DOI:

https://doi.org/10.1023/A:100638982825 9

Coulibaly YN, Mulia R, Sanou J, Zombre G, Bayala J, Kalinganire A, van Noordwijk M. 2014. Crop production under different rainfall and management 
conditions in agroforestry parkland systems in Burkina Faso: observations and simulation with WaNuLCAS model. Agroforest. Syst., 88:13-28. DOI : 10.1007/s10457-013-9651-8

Direction Générale de la Météorologie du Burkina Faso. 2013. Base de données climatiques du Burkina Faso. DGMBF, Ouagadougou.

Logbo J, Bada F, Gnancadja LS, Ameglio T, Akpo LE. 2011. Estimation de la biomasse racinaire en fonction de la teneur en eau du sol chez les espèces sahéliennes : cas d'Acacia tortilis (Forsk.) Hayne ssp. raddiana (Savi) Brenand et de Balanites aegyptiaca (L) Del, en station et en milieu naturel. Int. J. Biol. Chem. Sci., 5(1): 94-110. DOI: http://dx.doi.org/10.4314/ijbcs.v5i1.6809 0

Ndiaye SSA, Elhadji F, Tala G, Hank M, Camire C. 2012. Cordyla pinnata améliore les propriétés du sol et la productivité des cultures. Int. J. Biol. Chem. Sci., 6(2): 714-725. DOI: http://dx.doi.org/10.4314/ijbcs.v6i2.15

Petit S. 2003. Parklands with fodder trees: A fulse response to environmental and social changes. Appl. Geogr., 23(2-3): 205-22.

DOI:

10.1016/j.apgeog.2003.08.00

Sanou J. 2010. Optimizing the productivity of agroforestry parklands systems in West Africa using shade-tolerant annual crops. $\mathrm{PhD}$ thesis, Bangor University, United Kingdom, 209 p.

Sanou J, Bayala J, Teklehaimanot Z, Bazié P. 2012. Effect of shading by baobab (Adansonia digitata) and néré (Parkia biglobosa) on yields of millet (Pennisetum glaucum) and taro (Colocasia esculenta) in parkland systems in Burkina Faso, West Africa.
Agroforest. Syst., 85: 431-441. DOI: 10.1007/s10457-011-9405-4

Traore O, Some AN, Traore K, Somda K. 2007. Effect of land use changes on some important soil properties in cottonbased farming system in Burkina Faso. Int. J. Biol. Chem. Sci., 1(1): 7-14. DOI: http://dx.doi.org/10.4314/ijbcs.v1i1.3969 2

Teklehaimanot Z. 2004. Exploiting the potential of indigenous agroforestry trees: Parkia biglobosa and Vitellaria paradoxa in sub-Saharan Africa. Agroforest. Syst., 61: 207-220. DOI: https://doi.org/10.1023/B:AGFO.000002 9000.22293.d1

Tennant D. 1975. A test of a modified line intersects method of estimating root length. J. Appl. Ecol., 63: 995-1001. DOI: http://dx.doi.org/10.2307/2258617

Van Noordwijk M, Cadisch G. 2002. Access and excess problems in plant nutrition. Plant and Soil, 247: 25-40. DOI: https://doi.org/10.1023/A:102119462835 8

Van Noordwijk M, Rahayu S, Williams SE, Hairiah K, Khasanah N, Schroth G. 2003. Crop and tree root -system dynamics. In BelowGround Interaction in tropical Agroecosystems: Concepts and Models with multiple plant component, van Noordwijk M, Cadish G, Ong CK (eds). CABI: Wallingford (UK); 22-27.

Zomboudré G, Zombré G, Ouedraogo M, Guinko S, Roy Macauley H. 2005. Réponse physiologique et productivité des cultures dans un système agroforestier traditionnel : cas du maïs (Zea mays L.) associé au karité (Vitellaria paradoxa Gaertn.) dans la zone est du Burkina Faso. BASE, 9: 7585 . 